\title{
自然経過中に増大・新生を認めた未破裂脳動脈瘤の検討
}

\author{
沖井 則文, 田口 治義, 恩田 純, 栗栖 薰*
}

\section{Angiographical Growth of Unruptured Aneurysms in Their Natural History}

Norifumi OKII, M.D., Haruyoshi Taguchi, M.D., Jun Onda, M.D., and Kaoru KuRISU, M.D.*

Department of Neurosurgery, Hiroshima General Hospital and *Department of Neurosurgery, Hiroshima University School of Medicine, Hiroshima, Japan

Summary: The natural history of the unruptured aneurysm is not clear. We retrospectively analyzed 7 cases with 10 unruptured aneurysms and in the literature 18 similar cases with 23 aneurysms that expanded or newly formed due to natural causes.

In our series, the diameters of the aneurysms of the first angiograms were $A N 1(\mathrm{~mm}) 0$ to 28.63 (mean 8.40, median 6.45). Those of the last angiograms were AN2 ( $\mathrm{mm}$ ) 1.82 to 30.11 (mean 11.38, median 8.53). They were performed after 5.8 years of mean follow-up period: (=Int). The growth of the aneurysm diameter was $G(\mathrm{~mm})=A N 2-A N 1,1.47$ to $7.15(2.98 \pm 2.02)$. The growth rate was Gratio $(\mathrm{mm} / \mathrm{yrs})=G / \mathrm{Int}, 0.22$ to $2.52(0.71 \pm 0.70)$. In our series, 4 of 10 aneurysms were ruptured, and the remaining were intact. The mean diameter of the ruptured aneurysms expanded from $A N 1$ : 7.69 to AN2: 12.39 . The unruptured ones expanded from AN1: 8.87 to AN2: 10.70 . G of the ruptured aneurysm group was 4.70 . The unruptured group was 1.83 . Between these two $G$ s were significant differences. Gratio of the ruptured aneurysm group was 1.26 . The unruptured group was 0.34 . These two Gratios also had significant differences.

In our series AN2 of the ruptured aneurysm group was 12.39. This was larger than the unruptured group (10.70). This does not contradict findings in the literature that unruptured aneurysms whose sizes are over $7 \mathrm{~mm} \sim 10 \mathrm{~mm}$ have more risks of rupture.

Together with our series and the literature's, there were 18 de novo aneurysms. Five were so called "mirror image" aneurysms, so suspected one of the causes of the de novo aneurysm was congenital defect of the media, for example.

In our series the aneurysms whose $G \mathrm{~s}$ were equal to or grater than $2.5 \mathrm{~mm}$, or whose Gratios were equal to or greater than $20.49 \mathrm{~mm} /$ years ruptured. We therefore consider $2.5 \mathrm{~mm} \leqq \mathrm{G}$ or 20.49 $\mathrm{mm} /$ years $\leqq$ Gratio as risk factors.

We emphasize the need to estimate and follow up the sizes of the unruptured aneurysms with noninvasive examinations like MRA or CTA. If the sizes of the unruptured aneurysms are expanding by $2.5 \mathrm{~mm} \leqq G$ or $20.49 \mathrm{~mm} / \mathrm{years} \leqq$ Gratio, the aneurysms have more risks of rupture, so some kind of surgical intevention is recommended.

\author{
Key words: \\ - unruptured aneurysm \\ - growing up \\ - natural history \\ - cerebral angiography \\ - de novo
}

Surg Cereb Stroke (Jpn) 26: 106-112, 1998

厚生連広島総合病院 脳神経外科, *広島大学医学部 脳神経外科(受稿日 1997. 8. 22)〔連絡先： ₹ 732-0009 広島市東区戸坂千足 1-21-25 太田川病院 脳神経外科 沖井則文〕〔Mailing address: Norifumi OKII, M.D., Department of Neurosurgery, Ohtagawa Central Hospital, 1-21-25, Hesakasenzoku, Higashi-ku, Hiroshima 732-0009, Japan] 


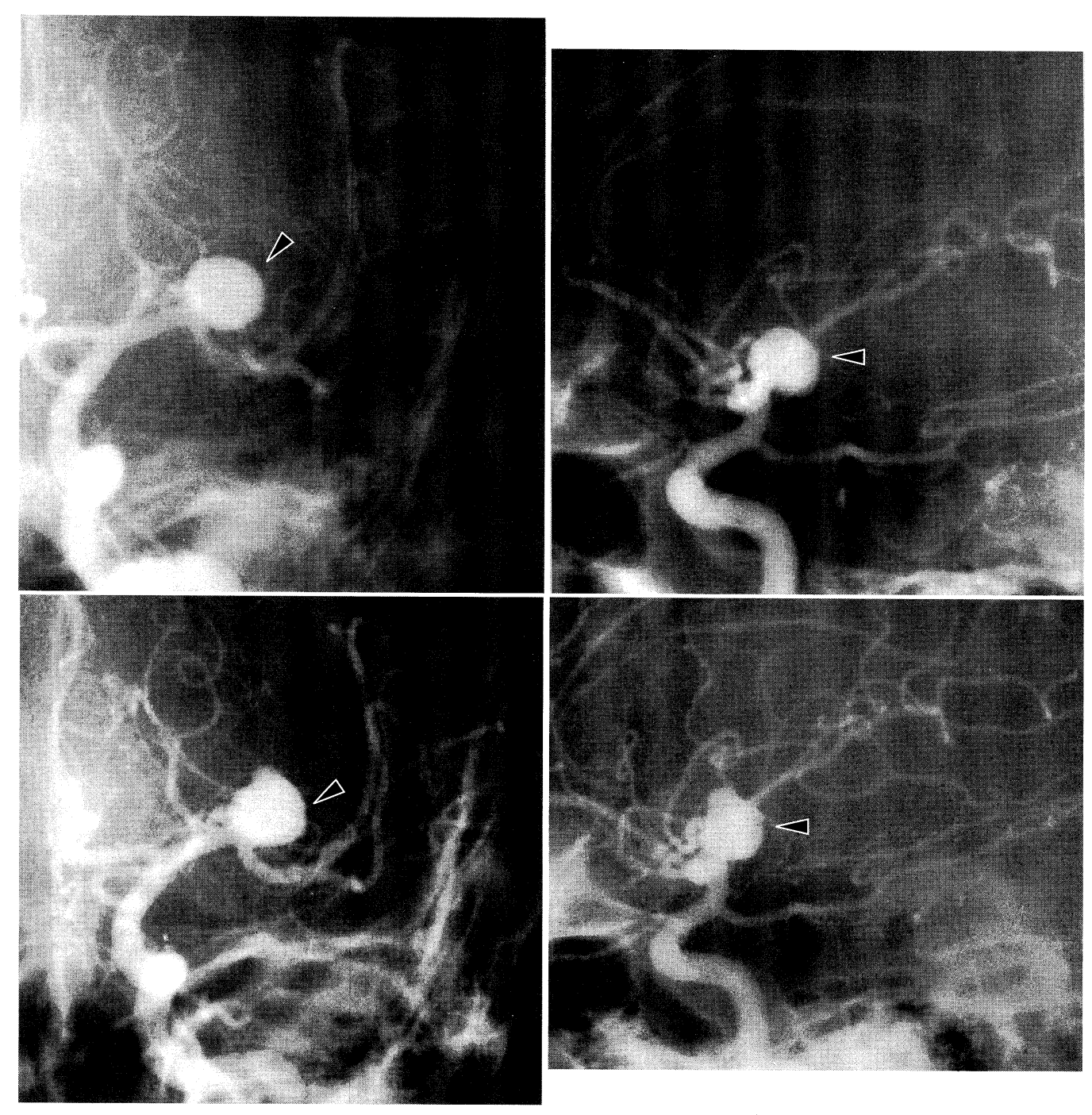

Fig. 1 Case 6: The first left carotid angiograms, on September 1987 (upper), demonstrating an $11.7 \mathrm{~mm}$ left middle cerebral aneurysm larrowhead, left: anteroposterior view, right: lateral view). The last left carotid angiogram, on September 1993 (lower), showing the aneurysm has expanded. Its diameter was $13.5 \mathrm{~mm}$ larrowhead, left: anteroposterior view, right: lateral view).

\section{はじめに}

MRA な゙の非侵襲的な脳血管障害のスクリーニングが 広く行われるようになり，未破裂脳動脈瘤の手術適応につ いて議論されることが多い.未破裂脳動脈瘤の手術の第一 の目的は，将来生じうる動脈瘤の破裂の予防であることは いうまでもない.しかし未破裂脳動脈瘤のすべてが破裂を きたすわけではなく, 未破裂脳動脈瘤の自然歴に関する研 究が望まれる。われわれは動脈瘤の増大に着目し, 自然経 過中に未破裂脳動脈瘤の増大・新生が認められた症例を対 象に, 未破裂脳動脈瘤の増大・新生と脳動脈瘤の破裂との 関係について retrospectiveに検討を加えた。

\section{対象および方法}

神経放射線学的に脳動脈溜の有無，大きさなどを評価可 能であった 197 例， 257 個の動脈瘤(破裂 177 個，未破裂 80 個)のうち，手術の影響あるいは血管狭窄，脳血管奇形 などの血流動態異常を有さない症例で, 自然経過において 経時的に増大・新生を確認できた未破裂脳動脈瘤 7 例 10 個を対象とした。血管撮影の画像はPICTファイルとして Macintosh コンピューターに読み込み, 画像処理ソフト NIH imageを用いて動脈瘤の長径を測定した。臨床経過, 動脈瘤の部位, 高血圧の有無, 性別などの因子と動脈瘤の 増大について検討した。 


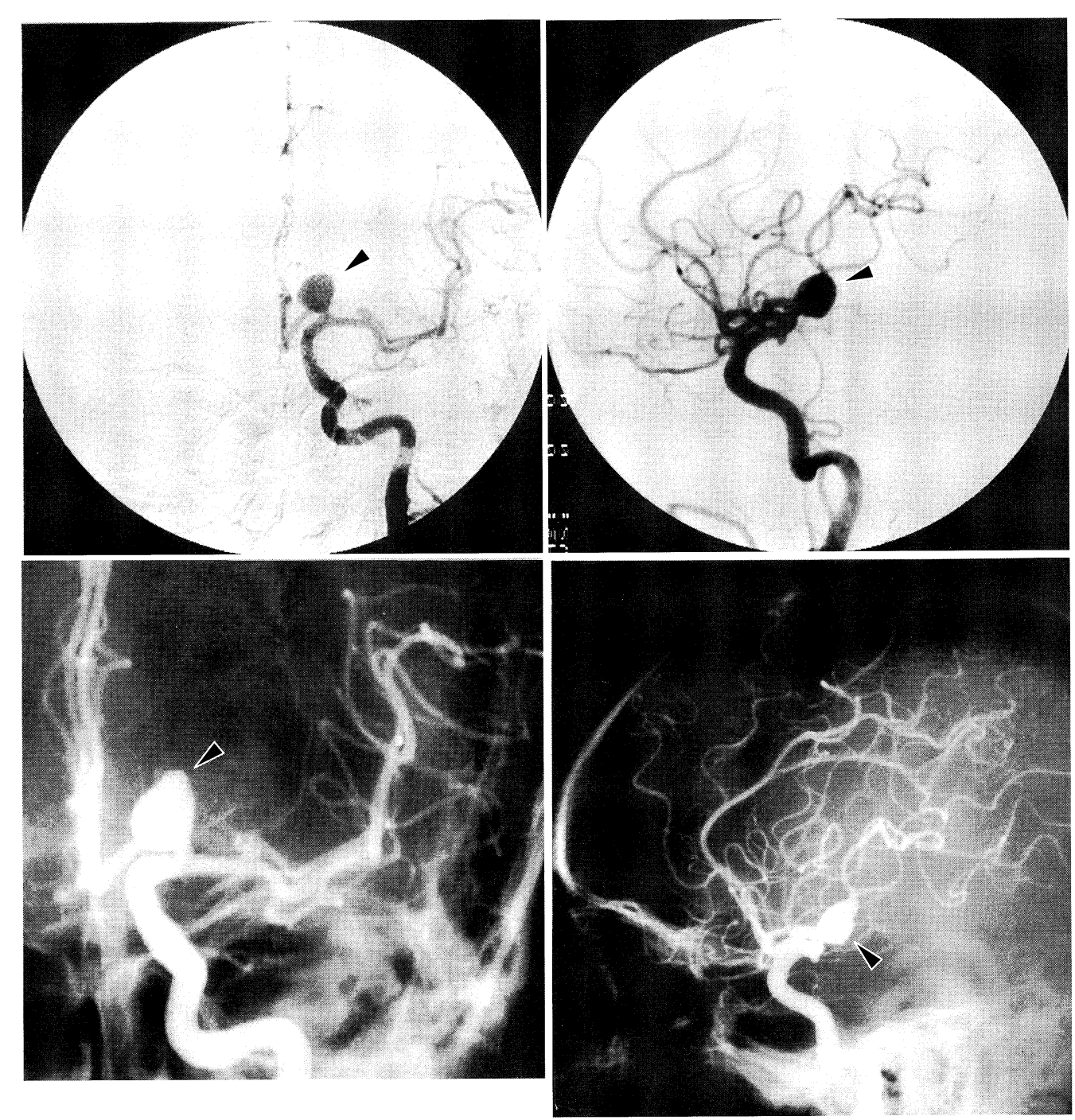

Fig. 2 Case 5: The left carotid angiograms, on January 1993 (upper), demonstrating a $12.6 \mathrm{~mm}$ left anterior cerebral aneurysm. larrowhead, left: anteroposterior view, right: lateral view). The last left carotid angiogram, on March 1994 (lower), showing the aneurysm has expanded. Its diameter was $15.5 \mathrm{~mm}$ larrowhead, left: anteroposterior view, right: lateral view).

\section{結 果}

年齢は 44 歳〜 74 歳 $(60.3 \pm 11.0), 10$ 個の動脈瘤の性別 は男性 3 例，女性 4 例 (多発例 1 例) であった。動脈瘤の発 生部位は中大脳動脈が 5 個, 内頸動脈が 3 個, 前大脳動脈 が 2 個であり, 中大脳動脈が最多であった。これらの動脈 瘤は 6 個がスクリーニング目的で行われた MRAにおいて 発見され，3個が多発脳動脈瘤に合併したくも膜下出血の 際に行った脳血管撮影において発見され，1個は動脈瘤に 起因する動眼神経障害をきたし, 発見されたものである

(Fig. 1, 2, Table 1). 経過観察期間 (以下 Int) は $1.2 \sim 14.7$

Table 1 Clinical summary of 7 cases (10 aneurysms)

\begin{tabular}{ccccccc}
\hline Case & Age & Sex & First AN & Second AN & Comp. 1 & Comp. 2 \\
\hline 1 & 44 & M & AcomA & Rt. MCA & SAH & SAH \\
2 & 56 & F & Lt. MCA & Rt. ACA & SAH & seizure \\
3 & 67 & F & Lt. ICA & Rt. ICA & SAH & SAH \\
4 & 72 & F & - & Rt. ICA & III N palsy & follow up \\
5 & 56 & $M$ & - & Lt. ACA & incidental & SAH \\
6 & 53 & $M$ & - & Lt. MCA & incidental & follow up \\
7 & 74 & $F$ & - & Rt. ICA & incidental & SAH \\
& & & Rt. MCA & & \\
& & & Lt. MCA & \\
& & Lt. MCA &
\end{tabular}

Abbreviations: First $\mathrm{AN}=$ location of the aneurysm detected on the first angiogram, AcomA=anterior communicating artery, $M C A=$ middle cerebral artery, $I C A=$ internal carotid artery, Second $A N=$ location of the aneurysm detected on the last angiogram, $\mathrm{ACA}=$ anterior cerebral artery, Comp. I=state of the patient at the time of the first angiography, Comp. 2=state of the patient at the time of the last angiography, SAH=subarachnoid hemorrhage, III N=oculomotor nerve 
Table 2 The growth and the growth rate of aneurysms etc. in our cases

\begin{tabular}{|c|c|c|c|c|c|c|c|c|}
\hline Case & Location & $\operatorname{lnt}(y r s)$ & $\mathrm{AN} 1(\mathrm{~mm})$ & $\mathrm{AN} 2(\mathrm{~mm})$ & $G(\mathrm{~mm})$ & Gratio (mm/yrs) & Hypertension & Rupture \\
\hline 1 & MCA & 3.1 & 4.63 & 7.13 & 2.50 & 0.80 & yes & yes \\
\hline 2 & $\mathrm{ACA}$ & 8.3 & 0.00 & 1.82 & 1.82 & 0.22 & yes & no \\
\hline 3 & $\mathrm{ICA}$ & 14.7 & 0.34 & 7.49 & 7.15 & 0.49 & yes & yes \\
\hline 4 & ICA & 3.9 & 28.63 & 30.11 & 1.48 & 0.37 & no & no \\
\hline 5 & $\mathrm{ACA}$ & 1.2 & 12.59 & 15.53 & 2.94 & 2.52 & no & yes \\
\hline 6 & MCA & 6.0 & 11.69 & 13.45 & 1.76 & 0.29 & no & no \\
\hline \multirow[t]{4}{*}{7} & ICA & 5.1 & 13.18 & 19.40 & 6.22 & 1.23 & yes & yes \\
\hline & MCA & 5.1 & 7.22 & 9.57 & 2.35 & 0.46 & & \\
\hline & MCA & 5.1 & 0.00 & 2.11 & 2.11 & 0.42 & & \\
\hline & MCA & 5.1 & 5.68 & 7.15 & 1.47 & 0.29 & & \\
\hline mean & & 5.8 & 8.40 & 11.38 & 2.98 & 0.71 & & \\
\hline rupture & & 6.0 & 7.69 & 12.39 & $4.70^{*}$ & $1.26 * *$ & & \\
\hline unrupture & & 5.6 & 8.87 & 10.70 & $1.83^{*}$ & $0.34^{* *}$ & & \\
\hline
\end{tabular}

Abbreviations: Int=time between the first and the last angiography, AN I=size of the aneurysm detected on the first cerebral angiogram, $A N 2=$ size of the aneurysm detected on the last cerebral angiogram, G=AN2-AN1, Gratio $=(A N 2-A N 1) / \operatorname{lnt}$

${ }^{*},{ }^{*}=$ Between groups of ruptured aneurysms and groups of unruptured ones were significant differences $(P<0.05)$.

(5.8土3.6) yearsである. 初回脳血管撮影時の動脈瘤の長 径(以下 AN1) は0〜28.63(mean 8.40, median 6.45) mmで あった(なお， $0 \mathrm{~mm}$ は初回の脳血管撮影時には動脈瘤が 認められなかったものである)。2回目の脳血管撮影時の 動脈瘤の長径(以下AN2) は 1.82〜30.11 (mean 11.38, median 8.53) mmであり, 経過観察中の動脈瘤長径の差 : $\mathrm{G}=\mathrm{AN} 2-\mathrm{AN} 1$ (以下 $\mathrm{G}$ ) は 1.47〜 7.15(2.98 2 2.02) $\mathrm{mm}$ であっ た. 1 年間あたりの動脈瘤の増大率 : Gratio $=\mathrm{G} / \mathrm{Int}$ (以下

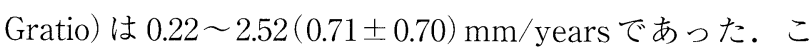
れら 7 例 10 個の動脈瘤のうち， 4 例 4 個が破裂した。

これらにつき統計学的検討を行った。検定はStudent's $\mathrm{t}$ 検定を行った．破裂群と非破裂群との比較では，AN1 は 破裂群 7.69 ，非破裂群 8.87 であり有意差はないが破裂群の ほうが小さかった。AN2は破裂群 12.39 ，非破裂群 10.70 でありその大きさは経過中に逆転していたＩntは破裂群 6.0, 非破裂群 5.6 であり有意差は認めなかった。Gは破裂 群 4.70, 非破裂群 1.83 であり破裂群の方が有意に増大して いた $(\mathrm{p}=0.0155)$. Gratio は破裂群 1.26 , 非破裂群 0.34 であ り，これも破裂群の方が有意に増大率が大きかった $(\mathrm{p}=0.0327)$. 高血压は 7 例中 4 例に認められ，うち 3 例 (75\%)が破裂をきたした(Table 2).

\section{考察}

\section{1. 未破裂脳動脈瘤の大きさと破裂}

一般に未破裂脳動脈瘤は巨大なものを除けば $10 \mathrm{~mm}$ 以 上のものが破裂しやすいといわれている 10) 12) 18) 19). Asari ら ${ }^{2)}$ は $9 \mathrm{~mm}$ 以下や $20 \mathrm{~mm}$ 以上のものと比較して 10 〜 $19 \mathrm{~mm}$ の動脈瘤は，より破裂のリスクが高いと述べて
いる. Inagawa $ら^{8)}$ の多発脳動脈瘤を有するくも膜下出血 24 症例の剖検例でも, 破裂した動脈瘤の $99 \%$ はその大き さが未破裂のものと比較して同径以上であったと報告して いる. Wiebers ら ${ }^{18)}$ 19) の未破裂脳動脈瘤 153 個，8年間の 経過観察では, $10 \mathrm{~mm}$ 以上の未破裂脳動脈瘤 51 個のうち $29 \%$ が破裂し，その長径は 10〜 $40 \mathrm{~mm}$ (平均 $21.3 \mathrm{~mm}$ ) で あった。一方長径 $10 \mathrm{~mm}$ 以下の未破裂脳動脈瘤 102 個は 破裂しなかった。したがって，10 mm 以下の未破裂脳動 脈瘤の破裂する確率は非常に低いと述べている。Juvela $ら^{9)}$ は未破裂脳動脈瘤 142 例 (181 個)を 10 年間, 経過観察 し，うち 27 例が破裂している. 彼らは破裂の予測因子は 動脈瘤の大きさであり， $7 \mathrm{~mm}$ 以上の動脈瘤はそれより小 さいものに比較して 2.18 倍破裂しやすいと述べている.

これらを総合するとやはり 7〜10 $\mathrm{mm}$ 以上の未破裂脳動 脈瘤は, それより小さい動脈瘤より破裂の頻度は多いと考 えられる。われわれのシリーズでも AN2 は破裂群 12.39 , 非破裂群 10.70 であり破裂群の方が動脈瘤が大きかった。

\section{2. 未破裂脳動脈瘤の増大・新生}

未破裂脳動脈瘤の増大・新生の報告例はいくつか散見さ れる 15)6(13) 14) 16)17). 新生例といわれるものの多くは，対 側内頸動脈結紮や狭窄あるいは azygos ACAなどの血管 奇形によってもたらされる, 脳血流動態の異常や, 手術部 位近傍の機械的，化学的な血管壁の変性に起因するものが 多い。それらの影響が及んでいない，純然たる de novo aneurysm や増大した動脈瘤の報告は少ない. Graf ら ${ }^{6)}$ は右中大脳動脈瘤クリッピング術の 3 年後に左中大脳動脈 瘤の新生した症例を de novo aneurysm として最初に報告 
Table 3 Review of 18 de novo aneurysms and 15 expanding aneurysms without any evident causes

\begin{tabular}{|c|c|c|c|c|c|c|c|c|c|c|c|c|c|c|c|}
\hline Author & Age & Sex & First AN In & $\operatorname{lnt}(y r s)$ & Second AN & New or Growth & Mirror image & $\begin{array}{l}\text { AN1 } \\
(\mathrm{mm})\end{array}$ & $\begin{array}{l}\text { AN2 } \\
|\mathrm{mm}|\end{array}$ & $\begin{array}{c}G \\
(\mathrm{~mm})\end{array}$ & $\begin{array}{l}\text { Gratio } \\
(\mathrm{mm} / \mathrm{yrs})\end{array}$ & Comp. 1 & Comp. 2 & Result & Hypertension \\
\hline \multirow[t]{10}{*}{ Our cases } & 44 & M & AcomA & 3.1 & Rt. MCA & Growth & & 4.6 & 7.1 & 2.5 & 0.8 & SAH & SAH & good & yes \\
\hline & 56 & $\mathrm{~F}$ & Lt. MCA & 8.3 & Rt. ACA & New & no & 0.0 & 1.8 & 1.8 & 0.2 & $\mathrm{SAH}$ & seizure & good & yes \\
\hline & 67 & $\mathrm{~F}$ & Lt. ICA & 14.7 & Rt. ICA & Growth & & 0.3 & 7.5 & 7.2 & 0.5 & SAH & SAH & poor & yes \\
\hline & 72 & $F$ & & 3.9 & Rt. ICA & Growth & & 28.6 & 30.1 & 1.5 & 0.4 & IIIN palsy & follow up & good & no \\
\hline & 56 & M & & 1.2 & Lt. ACA & Growth & & 12.6 & 15.5 & 2.9 & 2.5 & incidental & SAH & dead & no \\
\hline & 53 & M & & 6.0 & Lt. MCA & Growth & & 11.7 & 13.5 & 1.8 & 0.3 & incidental & follow up & fair & no \\
\hline & 74 & $F$ & - & 5.1 & Rt. ICA & Growth & & 13.2 & 19.4 & 6.2 & 1.2 & incidental & SAH & dead & yes \\
\hline & & & & 5.1 & Rt. MCA & Growth & & 7.2 & 9.6 & 2.3 & 0.5 & & & & \\
\hline & & & & 5.1 & Lt. MCA & Growth & & 0.0 & 2.1 & 2.1 & 0.4 & & & & \\
\hline & & & & 5.1 & Lt. MCA & Growth & & 5.7 & 7.2 & 1.5 & 0.3 & & & & \\
\hline Graf et al. (1964) & 39 & $F$ & Rt. MCA & 3.0 & Lt. MCA & New & yes & 0.0 & $?$ & & & SAH & SAH & dead & \\
\hline \multirow[t]{2}{*}{ Schievink et al. (1992) } & 57 & $F$ & Rt. PICA & 9.5 & Rt. $A C A$ & Growth & & $?$ & $?$ & & & $\mathrm{SAH}$ & $\mathrm{SAH}$ & good & \\
\hline & 41 & M & Rt. ICA & 4.0 & Rt. PICA & Growth & & 2.0 & 4.5 & 2.5 & 0.6 & SAH & $\mathrm{SAH}$ & good & \\
\hline \multirow[t]{7}{*}{ Nukui et al. (1982) } & 50 & $F$ & & 9.0 & Acom & New & no & 0.0 & 4.0 & 4.0 & 0.4 & head injury & SAH? & dead & yes \\
\hline & & & & 9.0 & Rt. ACA & New & no & 0.0 & 7.0 & 7.0 & 0.8 & & SAH? & & \\
\hline & 53 & F & Lt. ICA & 3.0 & Rt. ICA & New & yes & 0.0 & 6.0 & 6.0 & 2.0 & $\mathrm{SAH}$ & $\mathrm{SAH}$ & dead & no \\
\hline & 44 & $\mathrm{~F}$ & Rt. MCA & 3.5 & Rt. ACA & Growth & & 1.0 & 5.0 & 4.0 & 1.1 & $\mathrm{SAH}$ & SAH & good & no \\
\hline & & & Rt. MCA & 5.6 & Lt. ICA & Growth & & 4.0 & 9.0 & 5.0 & 0.9 & SAH & SAH & good & \\
\hline & 38 & $F$ & Rt. MCA & 5.3 & Acom & Growth & & 2.0 & 9.0 & 7.0 & 1.3 & $\mathrm{SAH}$ & SAH & dead & yes \\
\hline & 53 & $F \mathrm{t}$. & ICA, Lt. MCA & A 13.0 & Acom & Growth & & 2.0 & 8.0 & 6.0 & 0.5 & SAH & SAH & dead & no \\
\hline \multirow[t]{7}{*}{ Miller et al. (1985) } & 31 & $F$ & Lt. ICA & 3.0 & Rt. ICA & New & yes & 0.0 & 4.0 & 4.0 & 1.3 & SAH & $\mathrm{SAH}$ & poor & \\
\hline & 49 & $\mathrm{~F}$ & Lt. ICA & 11.0 & BA & New & no & 0.0 & 2.0 & 2.0 & 0.2 & SAH & SAH? & fair & \\
\hline & & & Lt. ICA & 11.0 & Rt. ICA & New & no & 0.0 & 2.0 & 2.0 & 0.2 & $\mathrm{SAH}$ & & & \\
\hline & 41 & $F$ & Rt. MCA & 5.0 & BA & New & no & 0.0 & $?$ & & & $\mathrm{SAH}$ & SAH & dead & \\
\hline & 30 & M & Rt. MCA & 4.0 & Acom & New & no & 0.0 & $?$ & & & SAH & SAH & good & \\
\hline & 51 & $F$ & Rt. ICA & 8.0 & Rt. MCA & New & no & 0.0 & 10.0 & 10.0 & 1.3 & SAH & SAH & poor & \\
\hline & 48 & $F$ & Rt. ICA & 20.0 & BA & New & no & 0.0 & 25.0 & 25.0 & 1.3 & $\mathrm{SAH}$ & $\mathrm{SAH}$ & dead & \\
\hline \multirow[t]{6}{*}{ Kubota et al. (1996) } & 52 & F & Rt. ICA & 14.0 & Lt. ICA & New & yes & 0.0 & $?$ & & & $\mathrm{SAH}$ & SAH & bad & \\
\hline & 51 & F & AcomA & 12.0 & Rt. ICA & New & no & 0.0 & $?$ & & & SAH & SAH & fair & \\
\hline & 39 & $M$ & Lt. MCA & 8.0 & Rt. MCA & New & yes & 0.0 & $?$ & & & SAH & SAH & dead & \\
\hline & 18 & $F$ & Lt. ICA & 8.0 & Rt. MCA & New & no & 0.0 & $?$ & & & $\mathrm{SAH}$ & SAH & fair & \\
\hline & & & & & Lt. ICA & New & no & 0.0 & $?$ & & & $\mathrm{SAH}$ & & & \\
\hline & & & & & Lt. ICA & New & no & 0.0 & $?$ & & & $\mathrm{SAH}$ & & & \\
\hline
\end{tabular}

Abbreviations: First $\mathrm{AN}=$ location of the aneurysm detected on the first angiogram, AcomA=anterior communicating artery, MCA=middle cerebral artery ICA=internal carotid artery, PICA=posterior inferior cerebellar artery, Int=time between the first and the last angiography, Second $\mathrm{AN}=$ location of the aneurysm detected on the last angiogram, BA=basilar artery, New=de novo aneurysm, Growth=expanding aneurysm, Mirror image=two aneurysms which are located in the symmetrical portion of bilateral cerebral arteries, ANI =size of the aneurysm detected on the first cerebral angiogram, AN2=size of the aneurysm detected on the last cerebral angiogram, G=AN2-AN1, Gratio=(AN2-AN1)/Int, Comp. 1=state of the patient at the time of the first angiography, SAH=subarachnoid hemorrhage, IIIrd N=oculomotor nerve, Comp. 2=state of the patient at the time of the last angiography

した.

われわれの増大・新生例はすべて血管奇形はなく，手術 の影響も及んでいない症例である。このような症例を文献

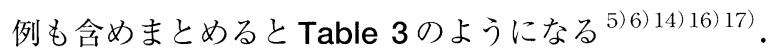

多くの de novo aneurysmの機序としては, hemodynamic stressが最も考えられている7111). しかし今回まと めた誘因の明らかでない de novo aneurysm 18 例中 5 例 は，対側の同一な部位に新生しており，いわゆる mirror imageである。このことより, de novo aneurysmの形成 には Crompton $^{4)}$, Graf ${ }^{6)}$ の提唱するように, 中膜の欠 損などの先天的な要因も加わっていると考えられる. hemodynamic stressは動脈瘤新生のみでなく動脈瘤増 大にも影響を及ぼす、実験的にAustin ${ }^{3)}$ は動脈瘤内圧 の上昇により，突然に動脈瘤径が増大することを報告して いる．貫井ら ${ }^{16)}$ は血管壁の変化と hemodynamic stress が動脈瘤の新生, 増大の原因であろうと述べている. 三平 ら ${ }^{13)}$ の破裂脳動脈瘤を含めた増大した動脈瘤の報告では 高血圧症が $71 \%$ ，血管奇形が $29 \%$ にみれ，hemodynamic factorをその原因にあげている。 また多発脳動脈瘤 も多く患者素因の問題もあげている。 Wiebers ら ${ }^{18)}{ }^{19)}$ は 脳動脈瘤は新生したのち, hemodynamic stressを受ける と比較的短期間のうちに増大し, 動脈瘤壁の弾性の限界を 
Table 4 Growth of the aneurysm diameter and its growth rate in our series and in the literature

\begin{tabular}{lcccccc}
\hline Author & Feature & No. of cases & AN1 $(\mathrm{mm})$ & AN2 $(\mathrm{mm})$ & $\mathrm{G}(\mathrm{mm})$ & Gratio $(\mathrm{mm} / \mathrm{yrs})$ \\
\hline \multirow{2}{*}{ Our cases } & Aneurysm rupture & 4 & 7.7 & 12.39 & $4.7^{*}$ & $1.26^{* *}$ \\
& No aneurysm rupture & 6 & 8.87 & 10.7 & $1.83^{*}$ & $0.34^{* *}$ \\
& mean & 10 & 8.4 & 11.38 & 2.98 & 0.71 \\
\hline \multirow{2}{*}{ Juvela (1993) } & Aneurysm rupture & 17 & 4 & 10 & 5 & 0.16 \\
& No aneurysm rupture & 14 & 4.5 & 5 & 0 & 0 \\
& mean & 31 & & & & \\
\hline
\end{tabular}

Abbreviations: $\mathrm{AN} 1=$ size of the aneurysm detected on the first cerebral angiogram, $\mathrm{AN2}=$ size of the aneurysm detected on the last cerebral angiogram, G=AN2-AN1, Gratio=(AN2-AN 1)/Int

$*^{*}{ }^{* *}=$ Between groups of ruptured aneurysms and groups of unruptured ones were significant differences $(\mathrm{P}<$ 0.051

超えると破裂し，それ以下であると，動脈瘤壁はコラーゲ ンで頑強に補強されるため, 破裂は免れると述べている.

\section{3. 未破裂脳動脈瘤の増大率}

文献上，明確に増大率に言及しているのは，渉猟しえた 範囲においては, Juvela $ら^{9)}$ の未破裂脳動脈溜 31 例，9年 の経過観察に基づいた報告があるのみである。ただし彼ら のシリーズに扔いて，破裂群は全例動脈瘤が増大している が, 未破裂群で增大したのは 1 例のみであり, 未破裂群に ついては本シリーズと比較できない(本シリーズのデー夕 は破裂群，未破裂群ともすべて増大した動脈瘤を対象とし ている)，彼らのシリーズに抢ける破裂群の動脈瘤につい てAN1は4,AN2は10であり，Gは5, Gratioは0.16と 述べている。本シリーズでは破裂群の AN1 は 7.69, AN2 は12.39, Gは4.70であり，Gについては彼らと同程度で あった。しかし本シリーズの破裂群の Gratio は 1.26 と彼 らより 7.9 倍大きくなった。これは彼らの破裂群の経過観 察期間は平均 9.1 年であり, 本シリーズのそれは平均 6 年 であったために, われわれの Gratio は大きくなったと考 えられた。またもともと本シリーズ破裂群の AN1 は彼ら のAN1よりも大きいため, より破裂しやすく, 増大率も 大きくなったものと考元られる(Table 4).

\section{4. 増大率と破裂との関係}

三平ら ${ }^{13)}$ の動脈瘤増大例 14 例の報告は破裂脳動脈瘤を 含めたものであるが，のちに動脈瘤の破裂または再破裂を 生じた症例の増大率は平均の増大率を上回っていたとして いる. 貫井ら ${ }^{16)}$ は 2 例 3 個の新生動脈溜と 3 例 4 個の未破 裂脳動脈瘤の増大例を報告しているが, 未破裂脳動脈瘤の 増大例はいずれも破裂をきたしている. Juvela ${ }^{9)}$ は未破 裂脳動脈瘤の 9 年間の自然経過において，31 例中破裂し た 17 例すべての動脈瘤が増大していたと報告し，破裂し なかった動脈瘤のうちで 14 例中 1 例のみが増大を示して いたに過ぎなったと報告している.
Table 5 Differences between the ruptured aneurysm group and the unruptured group

\begin{tabular}{ccc}
\hline & Rupture & Unrupture \\
\hline No. of cases & 4 & 6 \\
Gratio $(\mathrm{mm} / \mathrm{yrs})$ & $0.49 \leqq$ & $<0.49$ \\
$G(\mathrm{~mm})$ & $2.5 \leqq$ & $<2.5$ \\
\hline
\end{tabular}

The ruptured aneurysm group $(4 / 10)$ means $G$ is equal to or greater than 0.49 or Gratio is equal to or greater than 2.5.

Abbreviations: $G=$ =size of the aneurysm detected on the first cerebral angiogram)-(size of the aneurysm detected on the last cerebral angiogram), Gratio=G/(the time between the first and the last angiography)

われわれのシリーズでは経過中に破裂した 4 症例， 4 個 の動脈瘤はいずれも動脈瘤が $2.5 \mathrm{~mm}$ 以上増大し, 増大率 も $0.49 \mathrm{~mm} /$ years 以上であった。逆に動脈瘤が $2.5 \mathrm{~mm}$ 以 上増大したもの，あるいは増大率が $0.49 \mathrm{~mm} /$ years 以上の 動脈瘤はすべて破裂している。㑊しうち 2 例はくも膜下出 血が激しく，死亡している(Table 5).

まとめると未破裂脳動脈瘤は経過観察中に動脈瘤が増大 することがあり，その割合が大きく，動脈瘤壁の弾性を超 えるほどになると破裂に至る. そして $2.5 \mathrm{~mm}$ 以上の増大, $0.49 \mathrm{~mm} /$ years 以上の増大率は破裂の危険があるといえ る.

\section{5. 増大率と他の因子との関連}

Juvela $ら^{9)}$ の報告では増大率は性別, 平均血圧, 動脈瘤 の大きさ，年齢には関係ないと述べている．われわれのシ リーズでも高血圧例の $75 \%$ (3例 $/ 4$ 例 $)$ が破裂群に属してい たが，やはり Gや Gratio とは一定の関係は得られなかっ た。

\section{6. 評価方法}

動脈瘤は球体であり, その増大は 3 次元的に生じると予 想されるため, “真の”増大率を調べるためには動脈瘤の 
容積を比較することが望ましいと考えられる.しかしすべ ての動脈瘤において, follow upの際に, 画像情報より動 脈瘤の縦, 横, 高さを得ることは困難である. また仮にそ れらを知りえたとしても, 容積を求めるためには計算を行 わなければならず，非実用的である。ささら Juvela ら ${ }^{9)}$ の報告でも未破裂脳動脈瘤の唯一の破裂の予見因子は動脈 瘤の長径であり, 破裂と相関していたと述べている.した がって本シリーズに拈いて動脈瘤の増大率を求める際に は，動脈箇の長径を用いた。

\section{7. 破裂の予防}

未破裂脳動脈瘤は常に破裂の危険性を秘めており, その 危険性は $7 \mathrm{~mm}$ 以上が大きい. また動脈瘤が増大するもの, 増大率が大きいものはより破裂しやすい. 目安としては $2.5 \mathrm{~mm}$ 以上の増大， $0.49 \mathrm{~mm} /$ years 以上の増大率が危険 因子として考えられる。保存的に経過観察する場合には， 中川ら ${ }^{15)}$ のように，MRA，CTAなどの非侵襲的な検査 法を用いて, 最低, 半年〜 1 年に一度程度, 動脈瘤の形 状・大きさなどを評価することが肝要である.

\section{結論}

1. 自然経過中に増大・新生した未破裂脳動脈瘤を 7 例 (10 個) 経験した。

2. 未治療の未破裂脳動脈瘤には経時的な経過観察が必要 である。

3. 動脈瘤の平均の増大率は $0.71 \mathrm{~mm} /$ yearsであった。

4. $2.5 \mathrm{~mm}$ 以上の増大を示した 4 個の動脈瘤は破裂した.

5. $2.5 \mathrm{~mm}$ 以上の増大, $0.49 \mathrm{~mm}$ /years 以上の増大率は危 険因子である。しかし未破裂動脈瘤のすべてが破裂を きたすわけではなく，未破裂脳動脈瘤の自然歴に関す る研究が望まれる.

\section{文献}

1) Allock JM, Canham PB: Angiographic study of the growth of intracranial aneurysms. J Neurosurg 45: 617-621, 1976

2) Asari S, Ohmoto T: Natural history and risk factors of unruptured cerebral aneurysms. Clinical Neurology and Neurosurgery 95: 205-214, 1993
3) Austin GM, Schievink W, Williams R: Controlled pressurevolume factors in the enlargement of intracranial aneurysms. Neurosurgery 24: 722-730, 1989

4) Crompton MR: The pathogenesis of cerebral aneurysms. Brain 89: 797-814, 1966

5）久保田基夫, 星誠一郎, 砂田荘一, ほか：脳動脈瘤クリッ ピング術後の再発例・新生例の検討. 脳外誌 5: 29-36, 1996

6) Graf CJ, Hamby WB: Report of a case of cerebral aneurysm in an adult developing apparently de novo. J Neurol Neurosurg Psychiatry 27: 153-156, 1964

7) Gurdjian ES, Linder DW, Thomas LM: Experience with ligation of the common carotid artery for treatment of aneurysms of the internal carotid artery. J Neurosurg 23: 311-318, 1965

8) Inagawa $T$, Hirano A: Ruptured intracranial aneurysms: An autopsy study of 133 patients. Surg Neurol 33: 117-123, 1990

9) Juvela S, Porras M, Heiskanen O: Natural history of unruptured intracranial aneurysms: a long term follow-up study. J Neurosurg 79: 174-182, 1993

10) Kassell NF, Torner JC: Size of intracranial aneurysms. Neurosurgery 12: 291-297, 1983

11) Klemme WM: Hemorrhage from a previously undemonstrated intracranial aneurysm as a late complication of carotid artery ligation. Case report. J Neurosurg 46: 654-658, 1977

12) McCormick WF, Acosta-Rua GJ: The size of intracranial saccular aneurysms. An autopsy study. J Neurosurg 33: 422-427, 1970

13) 三平剛, 水野誠, 中島重良, ほか：Growing up Aneurysm 25例の検討. 脳神経外科 19: 825-830, 1991

14) Miller CA, Hill SA, Hunt WE: "De Novo" Aneurysms. A clinical review. Surg Neurol 24: 173-180, 1985

15）中川俊男, 端 和夫：脳ドッグにおける無症候性未破裂脳 動脈瘤の特徵と治療. 脳外誌 4: 341-350, 1995

16）貫井英明, 長屋孝雄, 宮城 修, ほか: 脳動脈瘤の成因甫 よび増大, 破裂に関する臨床的検討. Neurol Med Chir (Tokyo) 22: 437-445, 1982

17) Schievink WI, Piepgras DG, Wirth FP: Rupture of previously documented small asymptomatic saccular intracranial aneurysms. J Neurosurg 76: 1019-024, 1992

18) Wiebers DO, Whisnant JP, O’Fallon WM: The natural history of unruptured intracranial aneurysms. N Engl J Med 304: $696-698,1981$

19) Wiebers DO, Whisnant JP, Sundt TM Jr, et al: The significance of unruptured intracranial saccular aneurysms. J Neurosurg 66: 23-29, 1987 